\title{
APROXIMAÇÕES ENTRE A HISTÓRIA AMBIENTAL E A (IN)JUSTICA AMBIENTAL NA ABORDAGEM DA POLUIÇÃO INDUSTRIAL NO ESTUÁRIO DA LAGOA DOS PATOS, RS, BRASIL
}

\author{
Washington Luiz Ferreira*
}

\begin{abstract}
RESUMO
Discutem-se aproximações conceituais e pragmáticas plausíveis entre os domínios da História (História Ambiental) e do Direito (Justiça Ambiental), em relação ao tema específico da poluição industrial, utilizando como estudo de caso a região do Estuário da Lagoa dos Patos (RS, Brasil), com vistas a potencial (re)construção e aplicação da Justiça Social na área de estudo.
\end{abstract}

PALAVRAS-CHAVE: História ambiental. (In)justiça ambiental. Poluição industrial.

\begin{abstract}
We discuss plausible conceptual and pragmatic approximations between the domains of History (Environmental History) and Law (Environmental Justice), regarding the specific issue of industrial pollution, using as a case study the Lagoa dos Patos Estuary (RS, Brazil), with a view to the potential (re)construction and application of Social Justice in the study area.
\end{abstract}

KEYWORDS: Environmental history. Environmental (in)justice. Industrial pollution.

\section{INTRODUÇÃO}

Neste ensaio, procuramos desenvolver algumas aproximações conceituais e conexões empíricas entre os campos do conhecimento

Pesquisador associado ao Laboratório de Gestão Costeira Integrada -Universidade Federal de Santa Catarina - UFSC. 
da História, especificamente da História Ambiental, com o Direito e Justiça Social, por meio de suas interlocuções com os princípios da (In)Justiça Ambiental, utilizando como estudo de caso, a Poluição Industrial no Estuário da Lagoa dos Patos, RS, Brasil.

\section{A Área de Estudo}

A expressão "Mar de Dentro", corrente nas comunidades pesqueiras radicadas na região do Estuário do Sistema Lagunar Patos-Mirim (RS, Brasil), remonta ao período das primeiras expedições de navegantes portugueses e espanhóis na América Meridional. Estas comunidades, desde então, se reconhecem como pertencentes a este território, denominando-o (e especialmente a este Estuário, o qual conecta ambas as lagoas ao Oceano Atlântico) como o "Mar de Dentro", em complementação à outra área pesqueira regional, "Barra Afora", situada após a desembocadura do mesmo (FERREIRA, 2014).

Devido a sua localização geográfica (entre o litoral de Santa Catarina e o Rio da Prata) e características ambientais (com intensa mistura de águas límnicas e marinhas e consequente produtividade pesqueira), esta região estuarina revelou-se um ponto estratégico nas disputas entre as coroas portuguesa e espanhola ${ }^{1}$, permitindo adentrar ao território austral do Brasil em formação, o "continente de São Pedro do Sul", ainda no período colonial ${ }^{2}$.

Estes mesmos fatores foram determinantes na consolidação de

\footnotetext{
${ }^{1}$ Geopoliticamente, a expedição naval de Martim Afonso de Sousa deu o primeiro passo significativo, depois que Juan Días de Solís e Sebastião Caboto, sob bandeira espanhola, aportaram em Santa Catarina, em suas viagens ao Rio da Prata. Em 1531-1532, os irmãos Sousa percorreram a costa e deixaram informações substanciais. Pero Lopes [...] retornou a Lisboa em janeiro de 1533; um ano depois, em 1534, resultado das informações trocadas na Corte, na latitude aproximada do canal do Rio Grande, um estuário foi desenhado na "Carta náutica do Oceano Atlântico e Mar Mediterrâneo”, do português Gaspar Viegas (GOLIN. 2012: 1584).

${ }^{2}$ Data da segunda metade do século XVII uma das primeiras menções aos gados existentes nos campos daquilo que ainda viria a ser chamado de "O Continente do Rio Grande de São Pedro”. Assim diz, em 1663, o Padre da Companhia de Jesus Simão de Vasconcelos: "Daqui em diante [Rio Tramandaí] até o Rio da Prata, seguem-se as campinas já ditas, cheias de imensidade de gado, caça, cavalos, porcos monteses, e muitos outros gêneros que andam em bandos..." [Vasconcellos In Cesar, 1988: 34] (HAMEISTER, 2002: 32-33).
} 
um cenário e contexto geopolítico, construído historicamente, que imprimiu à região as funções estratégicas de centro logístico da produção agrícola, pesqueira e industrial, associadas ao comércio internacional portuário.

\section{MATERIAL E MÉTODOS}

$\mathrm{Na}$ perspectiva de compreensão dos fenômenos sociais, os fatos, isoladamente, pouco nos acrescentam; importa verdadeiramente o entendimento do seu encadeamento, de suas causas e consequências, dos processos e agentes envolvidos, ou seja, a dimensão do continuum entrelaçamento dos mesmos no decorrer da existência humana:

O que pode a história nos dizer sobre a sociedade contemporânea? O que ela pode fazer é descobrir os padrões e mecanismos da mudança histórica em geral, e mais particularmente das transformações das sociedades humanas durante os últimos séculos de mudanças radicalmente aceleradas e abrangentes. Em lugar de previsões ou esperanças, é isso que é diretamente relevante para a sociedade contemporânea e suas perspectivas (HOBSBAWM, 1998: 36-43, grifos nossos).

Para tal, entendemos como pertinente e necessário que o instrumental analítico e/ou referencial teórico possam contribuir na compreensão dos fenômenos pesquisados e na sistematização dos processos envolvidos; assim, adotamos o delineamento do campo de estudos na História Ambiental, segundo um dos seus quatro paradigmas:

a) da poluição, ou toxicológico; b) do equilíbrio ecológico ameaçado; c) dos recursos e entropia; d) da convivência. Os historiadores ambientais que trabalham com o paradigma da poluição aproximam-se dos historiadores da tecnologia e/ou da ciência; eles investigam a história da poluição e tentam reconstruir seu desenvolvimento (WINIWARTER, 2010: 06).

A expressiva assimetria na repartição social dos riscos e impactos derivados da apropriação e uso dos espaços e "recursos" 
naturais pelas atividades socioeconômicas, como a poluição industrial, pode ser assumida como indicadora fidedigna da Injustiça Ambiental $^{3}$. O silenciamento em relação à mesma contribui decisivamente para o incremento das desigualdades, injustiça e impactos socioambientais; neste sentido, esta imersão exploratória é assumida como um requisito imprescindível para o desvelamento da poluição industrial ${ }^{4}$, diretamente conectada ao referido paradigma da poluição (FERREIRA, 2017: 290-291).

Para situar espacialmente a proposta, utiliza-se do Estudo de Caso (YIN, 2015), circunscrevendo-o ao território do "Mar de Dentro", sobre o qual se dispõe de amplas fontes documentais, que ratificam a ocorrência e intensidade da poluição industrial na região. Argumenta-se, finalmente, sobre a pertinência da aproximação entre os citados campos do conhecimento, enquanto processo alinhado e eficaz na busca da construção da Justiça Social, face ao estabelecido (dentre outros) na Constituição Federal (BRASIL, 1988), que assegura o meio ambiente ecologicamente equilibrado como direito fundamental de tríplice dimensão: individual, social $e$ intergeracional (ROCHA, QUEIROZ, 2011).

\section{RESULTADOS E DISCUSSÃO}

\section{História da Industrialização Regional}

A dissociação e especialização excessiva do conhecimento acadêmico tem contribuído para a construção de uma versão da História econômica e política desmembrada da análise ambiental, o que vem colaborando para a disseminação de uma percepção fragmentada do contexto socioambiental local e regional

\footnotetext{
3 A desigualdade ambiental implícita no capitalismo liberalizado faz com que os danos decorrentes de práticas poluentes recaiam predominantemente sobre grupos sociais vulneráveis (ACSELRAD et al., 2012: 165).

4 Assumimos como Poluição Industrial o conjunto de alterações na qualidade da água, ar, solo, nutrientes, espécies, processos ecológicos e ecossistemas, decorrentes de atividades industriais diretas, e/ou daquelas atividades socioeconômicas que se utilizam de seus insumos, gerando efluentes com características industriais, cuja contaminação química resulte em depreciação e/ou danos à saúde e qualidade de vida, humana e não humana (FERREIRA, 2015).
} 
(FERREIRA, 2015: 51-52). A compreensão das interações e das consequências sobre os espaços, recursos e processos naturais, decorrentes das atividades socioeconômicas, é decisiva para a atuação de uma cidadania participativa. Neste sentido, a História Ambiental configura-se em elemento essencial para a rediscussão dos discursos e fatos estabelecidos, analisando criticamente o modo e as circunstâncias atuantes no percurso temporal humano:

Nos embates pelos protagonismos da e na História, de forma simplória, a contribuição da História Ambiental transcende a dualidade seres humanos/natureza para a construção de um amálgama analítico, que caminhe na direção das demandas sociais sobre o entendimento da interação entre seres humanos e natureza tanto no passado, quanto no presente (LOPES, 2010: 487, grifos nossos).

$\mathrm{Na}$ área de estudo, a produção agrícola (inicialmente de trigo e posteriormente de hortifrutigranjeiros), bem como a pesca, justificaram a implantação progressiva de um grande parque industrial destinado ao processamento de alimentos. Estas atividades abrangiam desde pequenos moinhos de cereais, fábricas de bolachas e biscoitos, o aproveitamento das frutas e hortaliças sazonais (doces em conserva) e, mais contemporaneamente, a produção de sucos de frutas, vinhos e refrigerantes:

O desenvolvimento de Rio Grande pode ser compreendido nos seguintes períodos distintos: a) a cidade político-militar (entre 1737 e 1821); b) a cidade comercial compacta, como gênese para o desenvolvimento urbano e fabril (entre 1822 e 1872); c) a primeira fase industrial (entre 1874 e 1969); d) a segunda fase industrial (entre as décadas de 1970 e 1980). O período áureo para a cidade estendeu-se de 1874 (implantação do primeiro grande parque fabril), até 1930 (...). Este importante ciclo industrial conheceu seu declínio nas décadas de 1950 e 1960. Do período fabril, compreendido entre a industrialização dispersa (1874/1930) e a industrialização restringida (1930/1969), houve a instalação de mais de 30 empresas fabris de médio e grande porte (MARTINS, 2007: 08, grifos nossos).

O desdobramento e a crescente incorporação tecnológica por parte destas atividades contribuiram para a diversificação de suas 
linhas de atuação e a ampliação da intensidade de uso dos espaços e "recursos" naturais, atraindo atividades complementares e fornecedoras, até a implantação do seu Distrito Industrial, ainda na década de 1970 (Tab. 01).

TABELA 1 - Cronologia da Industrialização no Estuário da Lagoa dos Patos

\begin{tabular}{|c|l|l|}
\hline $\begin{array}{c}\text { Categorias de } \\
\text { atividades }\end{array}$ & \multicolumn{1}{|c|}{ Atividades industriais específicas } & Início \\
\hline \multirow{5}{*}{$\begin{array}{c}\text { Processamento de } \\
\text { alimentos e derivados }\end{array}$} & Charqueadas & 1777 \\
\cline { 2 - 3 } & Sebo, sabão e velas & 1856 \\
\cline { 2 - 3 } & Moinhos de cereais & 1864 \\
\cline { 2 - 3 } & Massas e biscoitos & 1894 \\
\cline { 2 - 3 } & Cebidas & 1889 \\
\cline { 2 - 3 } & Frigoríficos (carne bovina e ovina) & 1906 \\
\cline { 2 - 3 } & Conservas de pescados & 1917 \\
\cline { 2 - 3 } & Óleos vegetais & 1937 \\
\cline { 2 - 3 } & Refrigerantes & 1939 \\
\hline \multirow{5}{*}{ Minas e energia } & Mineração de carvão & 1948 \\
\cline { 2 - 3 } & Mineração de minérios metálicos & 1792 \\
\cline { 2 - 3 } & Dragagens portuárias & 1825 \\
\cline { 2 - 3 } & Usina termoelétrica a carvão & 1905 \\
\cline { 2 - 3 } & Refinaria de petróleo & 1908 \\
\hline \multirow{5}{*}{ Outros } & Tecelagens & 1937 \\
\cline { 2 - 3 } & Cigarros e charutos & 1873 \\
\cline { 2 - 3 } & Curtumes e calçados & 1891 \\
\cline { 2 - 3 } & Cordas e cabos náuticos & 1914 \\
\cline { 2 - 3 } & Estaleiros & 1950 \\
\cline { 2 - 3 } & Fertilizantes Sintéticos & 1973 \\
\cline { 2 - 3 } & Siderurgia e metalurgia & 0 . \\
\hline
\end{tabular}

FONTE: adaptado de História da Industrialização no "Mar de Dentro" (cap. IV; pp: 63-105) in: FERREIRA, 2016.

A este esboço cronológico da industrialização regional, devem-se acrescentar os reflexos da revitalização da indústria naval do país, materializada no Polo Naval de Rio Grande e São José do Norte e a emergência dos Parques Eólicos regionais (na década de 2010). Além das atividades industriais instaladas diretamente neste 
estuário, o mesmo e boa parte das bacias hidrográficas que a ele convergem (Lagoa dos Patos e Lagoa Mirim) encontram-se inseridos em uma região de intenso desenvolvimento agrícola, industrial e portuário, do qual resulta um quadro contextual de contínua poluição, incidindo sobre seus ambientes e populações ${ }^{5}$.

\section{Impactos Socioambientais da Poluição Industrial}

A sucessão, sobreposição e sinergia dentre as diferentes atividades industriais na região vem gerando, ao longo do tempo, um expressivo grau de poluição dos ares, águas, solos e sedimentos, contaminação da flora e da fauna e das populações humanas, assim como desencadeando ou incrementando muitos conflitos socioambientais. Tais atividades geraram (e continuam a influenciar) um grande passivo de degradação das condições ambientais e da qualidade de vida. Como convém ao protocolo macroeconômico, estas depreciações tendem a ser interpretadas como meras "externalidades" do processo industrial, de modo a não macular a imagem idealizada da região (frente a potenciais investidores) e/ou minimizar a responsabilidade socioambiental de seus gestores.

Como desencadeador desta situação, a região foi inserida, já no início da colonização portuguesa, no modelo de reprodução do capital, ao qual só interessa garantir a expansão contínua da lucratividade dos investimentos aplicados, desconsiderando-se os custos e impactos socioambientais, modelo ainda dominante e hegemônico, a despeito dos discursos políticos e publicitários, que procuram renovar sua imagem, sob o rótulo de Desenvolvimento Sustentável e afins ${ }^{6}$ :

${ }^{5}$ Para mais detalhes sobre os processos industriais e impactos ambientais associados à Poluição Industrial na região, revisitar: STENZEL, L.; FOELKEL, C.; GALLARDO, 1998; LAYBAUER, 1998; AGOSTINETTO et al., 2000; DEMORE, 2001; VANZ, MIRLEAN, BAISCH, 2003; LOPES, 2006; BUNDT et al., 2010; NÓBREGA, KRUSCHE, 2010.

${ }^{6}$ Desde 1972, várias tentativas recolocavam no cenário internacional um novo conceito de desenvolvimento - resultaram, inclusive, nas formulações denominadas de "outro desenvolvimento", "desenvolvimento endógeno" $e$ "ecodesenvolvimento". Contudo, elas não atendiam plenamente às expectativas políticas dos órgãos e das instituições internacionais [...] de proporcionar um alinhamento em torno da possibilidade de unir meio ambiente e crescimento 
Apesar da incorporação semântica do conceito de sustentabilidade nas políticas públicas regionais, o modelo de desenvolvimento $e$ gestão ambiental em curso na Planície Costeira do Rio Grande do Sul (RS, Brasil) prossegue sendo orientado por estratégias e programas que desconsideram a complexidade das interações entre o seu expressivo passivo socioambiental e as crescentes demandas sociais e pressões político-econômicas (FERREIRA, CIPRIANO, MACHADO, 2010: 03).

Localizada no epicentro deste sistema estuarino, a cidade de Rio Grande é reconhecida, há muito, como uma cidade das chaminés ${ }^{7}$, numa clara alusão à grande concentração da produção industrial. Em decorrência, apresenta um histórico de intensa contaminação pelos efluentes industriais e derivados, a maior parte dos quais acaba chegando aos ambientes costeiros (NIENCHESKI, 2000), contaminando toda cadeia trófica aquática e o conjunto de seus usuários.

Segundo Fonseca (2007), a Fundação de Estatística do Estado, através do seu Índice de Potencial Poluidor da Indústria, considera Rio Grande como um município crítico em termos de poluição industrial. Tal contexto de insalubridade e periculosidade, associado à poluição industrial, é claramente percebido por uma pequena parcela da população - os trabalhadores do setor industrial e moradores do entorno - diretamente exposta a estes agentes:

... efetiva percepção por parte dos depoimentos de trabalhadores (...) da poluição atmosférica provocada pelo processo de produção de fertilizantes sintéticos no município de Rio Grande, bem como das

econômico, sem questionar a continuidade do sistema (FREITAS, NUNES, NELSIS, 2012: 45).

7 Até a década de 1920 [...], escritos de militantes operários descrevem uma paisagem de chaminés, galpões industriais, maquinismos e toda a sorte de inovações técnicas [...] celebrado como sinais de um devir utópico, no qual a sujeição da natureza prometia ruptura com o império da necessidade (GANDRA, SILVEIRA, 2012: 81).

8 Referimo-nos, dentre outros, aos efluentes da fabricação de fertilizantes (MIRLEAN; OSINALDI, 2004), metais pesados (BENDATI; DICK, 2007; FRAGOMENI et al., 2010; SILVA, 2011), agrotóxicos (SÁ, 2006) e hidrocarbonetos aromáticos policíclicos (THEODOSIO, 2002), agentes mutagênicos e carcinogênicos ao homem e aos animais (JACQUES et al., 2007). 
suas implicações em termos de insalubridade para os operários e nos transtornos respiratórios para a população local (SANCHEZ, FERREIRA, GALIAZZI, 2011).

Paradoxalmente, entretanto, a maior parte da população local parece não perceber ou se sentir atingida por tais circunstancias. Estas contradições sugerem um problema de fundo bastante sério, que requer uma abordagem mais ampla para sua superação, cujas causas podem estar vinculadas a produção e disseminação de discursos que invisibilizam ou negam a poluição industrial e seus efeitos na região.

\section{Discursos e as imagens disseminados e ocultados}

Analogamente ao tema e metáfora da "Primavera Silenciosa" (desenvolvida por Raquel Carson, 1969), o "Mar de Dentro" e região adjacente também tem sido palco de muitos eventos agudos e processos crônicos de intensa poluição industrial, cujas ocorrências e resultados tendem a ser "naturalizados". A historiografia oficial assegura a perpetuação da imagem de empreendedorismo e relevância socioeconômica dos ícones do desenvolvimento industrial; estes registros constroem e reproduzem o discurso da importância socioeconômica destas atividades, mas se calam completamente em relação aos impactos socioambientais (dentre outros) da poluição industrial gerada pelas mesmas. Esta construção de uma "verdade relativa", sempre favorável à imagem de tais empreendimentos, constitui-se em instrumento habitual da mídia e disponível para quaisquer "clientes" interessados:

Se o que é visibilizado na mídia jornalística está implicado com a produção de modos de existência, é preciso ir além das evidências (...), do que é apresentado como verdade "natural", para pensar sobre o que está sendo enunciado e oferecido nesse jogo de informações e dramatizações, que constitui possibilidades de subjetivação aos indivíduos. Pois brechas a outras composições são possíveis a despeito do que as luzes do enfoque midiático nos mostram (e nos ensinam) como modos de ser ou não ser no contemporâneo (RODRIGUES; HENNIGEN, 2011: 55). 
Nesse sentido, as imagens e discursos reificados e/ou negados continuamente acabam por assumir, no imaginário social, o sentido de realidade, reforçando a lógica e os valores do modelo de desenvolvimento em curso, desqualificando os argumentos, fatos e opiniões divergentes, dentre os quais aqueles relativos à denúncia e/ou discussão sobre os impactos socioambientais da poluição industrial gerada por este modelo de desenvolvimento:

Ciência e tecnologia são herdeiras dos mais poderosos mitos da civilização ocidental, cavalgando promessas de progresso ilimitado, de organização racional da vida social, política e econômica, e de subjugação do mundo social e natural aos desejos e ao planejamento de decision-makers iluminados pelo saber [...]. A tecnotopia, caudatária da ideologia do progresso e de uma visão evolutiva da história da tecnologia (especialmente a partir da Revolução Industrial), é hegemônica e, neste momento de crises de utopias, é, em larga medida, o grande metarrelato salvífico do mundo contemporâneo (RIBEIRO, 1999: 02-03).

Nesse cenário, as questões socioambientais tendem a ser convertidas, de obstáculos à implantação ou expansão industrial, em peças do "marketing verde" destes conglomerados (FERREIRA, 2016: 193). Assim, a memória individual e coletiva ${ }^{9}$ pode ser induzida à negação de alguns aspectos de seu passado, remetendo para o "arquivo-morto" os riscos e impactos percebidos/vividos ao longo do processo de desenvolvimento. Este comportamento poderia estar associado com a tendência da sociedade em preservar, para a posteridade, somente os aspectos "positivos" dos empreendimentos, legando-nos os seus documentos/monumentos (sensu LE GOFF, 1994), e de negar, para as gerações futuras, o acesso aos problemas vividos. Tais documentos/monumentos podem circunscrever, não apenas os objetos e estruturas vestigiais de uma determinada cultura, mas abarcar todo o conhecimento gerado por esta.

\footnotetext{
${ }^{9}$ A rememoração individual se faz na tessitura das memórias dos diferentes grupos com que nos relacionamos. Ela está impregnada das memórias dos que nos cercam, de maneira que [...] o nosso lembrar e as maneiras como percebemos e vemos o que nos cerca se constituem a partir desse emaranhado de experiências, que percebemos qual uma amálgama, uma unidade que parece ser só nossa (KESSEL, s/d: 03).
} 
A Sinergia das Atividades Socioeconômicas e dos Impactos Associados

Os processos industriais são muito dinâmicos e integrados em sua estratégia de ocupação territorial e apropriação dos "recursos naturais". Com a retomada da indústria naval na região ${ }^{10}$, além dos conflitos e injustiças ambientais diretamente associados, vem ocorrendo a atração de novos projetos de "desenvolvimento" (SANTOS; MACHADO, 2013b), o que faz desse território uma grande "zona de sacrifício" e/ou "paraíso de poluição"11 (SANTOS; MACHADO, 2013a).

Um novo aporte maciço de recursos, imbricados com as estratégias geopolíticas, condicionam este estuário enquanto complexo portuário-industrial (GOMES, 2013: 101-102), como peça chave de sua rede de compromissos transnacionais ${ }^{12}$ :

Estes problemas potenciais tendem a serem agravados com a expansão do setor industrial-portuário, e as tradicionais medidas de "ajuste ambiental" empregadas no seu licenciamento e monitoramento ambiental, incrementando ainda mais os impactos socioambientais já recorrentes no cenário local. A releitura da História Ambiental regional é essencial para a compreensão das conexões causais de muitos dos problemas de saúde humana e de

\footnotetext{
${ }^{10}$ Rio Grande vem recebendo, desde 2005 plataformas oceânicas que possuem a finalidade de produzir e beneficiar petróleo e gás. A partir de então, há encomendas de cascos de plataformas para exploração de petróleo do tipo FPSOs - floating production, storage and offloading: realizam a prospecção, a perfuração $e$ a exploração do petróleo em alto mar, e semissubmersíveis - plataformas que apenas exploram, não armazenam, além de Navios Sonda, para a perfuração de poços submarinos (ALMEIDA, 2015: 67).

${ }^{11}$ Nestes locais, além da presença de fontes de risco ambiental, verifica-se também uma tendência a sua escolha como sede da implantação de novos empreendimentos de alto potencial poluidor. Tais localidades são chamadas, pelos estudiosos da desigualdade ambiental, de 'zonas de sacrificio' ou 'paraísos de poluição', onde a desregulação ambiental favorece os interesses econômicos predatórios, assim como as isenções tributárias o fazem nos chamados 'paraísos fiscais' (SANTOS, 2014: 03).

12 Os investimentos no setor naval, somente por parte de negócios ligados a Petrobras, incluindo as plataformas P-55 e P-63, o dique-seco e a construção de cascos devem gerar em cinco anos algo em torno de 40 mil empregos diretos $e$ indiretos. São projetados para o polo naval de Rio Grande, até o ano de 2015, investimentos no montante de R\$14 bilhões (FEIJÓ; MADONO, 2012: 05).
} 
degradação ambiental vigente, bem como para a perspectiva de reordenamento dos processos produtivos (SANCHEZ, FERREIRA, GALIAZZI, 2011).

\section{O Licenciamento Ambiental e o Princípio do Poluidor-Pagador}

Na perpetuação do cenário em curso, e muito provavelmente, no incremento dos problemas constatados, incidem estes dois instrumentos utilizados no processo de gestão ambiental, os quais interagem diretamente, especialmente em territórios com alto grau de diversificação e sobreposição de atividades socioeconômicas.

No complexo e imprescindível sistema de licenciamento ambiental destas atividades, que procura planejar a utilização dos espaços e "recursos" naturais, garantindo os benefícios socioeconômicos das mesmas, e minimizar os impactos sobre os ecossistemas que lhes dão suporte, ainda persiste uma visão individualizada e isolada de cada empreendimento, subestimando os efeitos decorrentes da sua escala de desenvolvimento setorial, as interações com outras atividades e os efeitos sinérgicos de ambos sobre a qualidade ambiental regional.

Embora concebido de modo a resguardar a responsabilização pelos danos e impactos provocados ao meio ambiente pelos respectivos agentes causadores, a aplicação irrestrita e acrítica do Princípio do Poluidor-Pagador ${ }^{13}$ tem se revelado contraproducente, inócua e, muitas vezes, contraditória e perversa, porque viabiliza sua apropriação e reversão pelos agentes degradantes, configurando - na prática - o direito de poluir, ou seja, sendo pagas as licenças ambientais e as multas incidentes na legislação, o empreendedor assegura o "direito" de continuar poluindo, eximindo-se assim da responsabilidade de evitar o dano e adaptar seu processo produtivo, de modo a torna-lo mais adequado a manutenção da qualidade de vida na região onde se insere; esta possibilidade (já efetiva no cotidiano) torna a aplicação de tal princípio um instrumento de perpetuação da Injustiça Ambiental.

${ }^{13}$ O princípio [do Poluidor-Pagador] garante que haja responsabilidade por parte dos poluidores e, em consequência, equilibra o mercado, conscientiza produtores $e$ consumidores, fomenta atitudes preventivas que são mais sedutoras no contexto de precisa alocação de custos e responsabilidades (LIMA, MOREIRA, 2014: 06). 
Diretamente conectado ao sistema de licenciamento ambiental, e a aplicação do Princípio do Poluidor-Pagador, e como tais, também concebido para melhor gerir as questões socioambientais, outro instrumento vem sendo consagrado: o sistema de automonitoramento $^{14}$, pelo qual caberia ao empreendedor analisar e quantificar as especificidades (e irregularidades) ambientais verificadas no seu processo produtivo, informando-as regularmente aos órgãos gestores; tal procedimento abre a possibilidade para a sonegação e manipulação de informações essenciais a (dentre outros) prevenção e controle da poluição industrial.

Situado entre a pseudo ingenuidade e a irrestrita liberalidade, este procedimento segue a tendência crescente de enxugamento da estrutura e função pública, na esteira da onda privatizadora que prega o advento do Estado mínimo ${ }^{15}$, com repercussões muito negativas quanto à garantia de qualidade ambiental, por tacitamente autorizar o empreendedor a decidir quando, se e como vai atuar na reversão das irregularidades (quando, eventualmente, reconhecer sua existência).

\section{O papel da Universidade na promoção da Justiça Social}

A Universidade é reconhecida como um centro de excelência na produção e difusão do conhecimento sobre, com e para as comunidades de sua região de inserção; desta prerrogativa deriva também uma grande responsabilidade, o seu papel enquanto agente público decisivo na promoção da justiça social, pela efetiva promoção da pesquisa e discussão pública sobre os problemas

\footnotetext{
${ }^{14} \mathrm{O}$ automonitoramento das fontes poderá contribuir com os sistemas de avaliação das agencias ambientais públicas, medindo suas próprias emissões, descargas através de indicadores de desempenho, que possam ser avaliados através de relatórios $e$ informações sobre a natureza das descargas de poluentes ou de sua origem tecnológica. Sua utilização poderá permitir a redução de custos de inspeção e dividir os custos de implantação da rede de monitoramento com a comunidade regulada, porém deverão implicar em programas de auditoria e verificação de resultados pelas agencias, de acordo com sua função reguladora (MAGLIO, 2000: 224-225).

${ }^{15}$ A implementação dessas políticas foi possíveis face à construção de um consenso que se formou em torno da inexorabilidade das reformas como única alternativa para amenizar as desigualdades sociais. Passados 18 anos desse processo, os indicadores sociais recalcitrantes indicam que nossa democracia é absolutamente desarticulada das relações de liberdade e igualdade, valores universais desprezados na América Latina (FARIAS, 2008: 10).
} 
relativos às suas comunidades. Contudo, no caso em foco, a ausência de discussão ou a "invisibilidade" relativa do tema da poluição industrial no conjunto da produção acadêmica (FERREIRA, 2014: 135; FERREIRA, 2017: 297) da Universidade pública local, a qual tem como lema e missão institucional a pesquisa e conservação dos ecossistemas costeiros e marinhos adjacentes (SCHMIDT FERIS, 2004), revela um emaranhado de contradições socioambientais que se perpetuam.

Quando, ao processo de negação, enquanto mecanismo psicológico de defesa individual ${ }^{16}$, se articula a sonegação de informações para a sociedade, os resultados podem ser muito graves, pelas dificuldades de reversão dos mesmos, face à inércia coletiva resultante ou reforçada pela não percepção factual.

\section{A (Re)Construção da Justiça Social na Prevenção e Controle da Poluição Industrial}

Apesar dos problemas elencados no cenário relativo ao disgnóstico, percepção e gestão da poluição industrial na região, entende-se que os instrumentos legais disponíveis podem e devem ser utilizados e aperfeiçoados para fazer valer, efetivamente, os direitos e a justiça social relativos a qualidade ambiental:

$\mathrm{O}$ direito ao meio ambiente ecologicamente equilibrado, embora não esteja no Título dos Direitos e Deveres Individuais é, indubitavelmente, por meio de uma leitura sistemática da Constituição e, necessariamente, da Política Nacional do Meio Ambiente, preponderantemente indispensável à concepção protetiva tendente a transformar o Estado de Direito Democrático em Estado de Direito Ambiental, englobando a ideia de preservação como Direito e Dever do homem (SARAIVA, VERAS NETO, 2013, grifos nossos).

Para viabilizar tal (re)construção, faz-se necessário promover a ampla e profunda discussão dos temas tratados, como estímulo a participação cidadã qualificada sobre os mesmos, de modo a tensionar os respectivos representantes da população junto aos

\footnotetext{
${ }^{16}$ A 'Negação' é a tentativa de não aceitar na consciência algum fato que perturba o Ego. Os adultos tem a tendência de fantasiar que certos acontecimentos não são, de fato, do jeito que são, ou que nunca aconteceram (VOLPI, 2008: 03).
} 
poderes instituídos, para a revisão e aperfeiçoamento do referido instrumental. Neste aspecto, o resgate do caráter crítico, propositivo e proativo da Universidade, em conjunto com as organizações comunitárias e não governamentais, pode vir a desempenhar relevante papel social, abrindo-se às demandas e necessidades das comunidades as quais se destinam, questionando-se o modelo de desenvolvimento em curso e a desigual distribuição dos ônus e bônus do mesmo, propondo um modelo autônomo, social e ambientalmente referenciado de desenvolvimento para a região ${ }^{17}$, no qual se estruturem condicionantes tais que inibam a implantação de novos empreendimentos poluidores e que sejam eficazes no rigoroso controle da poluição daqueles já estabelecidos e operantes.

Para operacionalizar esta nova concepção de desenvolvimento regional, também há de ser revisto todo o processo de licenciamento e monitoramento ambiental das atividades socioeconômicas, substituindo grande parte do modelo usual, ainda muito protocolar e clientelista, por uma visão ampliada e integrada do território, através da Avaliação Ambiental Estratégica ${ }^{18}$, (re)desenhando um conjunto de potenciais atividades complementares, compatíveis e interatuantes com a heterogeneidade espacial e a biosociodiversidade regional, $a$ priori, mais consistentes com a perspectiva almejada de justiça social.

\footnotetext{
${ }^{17}$ A esse respeito, dentre as recentes políticas públicas do Brasil: ...no Ministério do Meio Ambiente, destaca-se o Programa de Desenvolvimento Socioambiental da Produção Familiar Rural (Proambiente), implementado a partir da iniciativa dos movimentos sociais e que, depois de 2003, passou a ser um programa de política pública [...] com a preocupação de promover sistemas de produção e atividades adaptados ao entorno ambiental local, com o intuito de melhorar a situação dos agricultores familiares (BONNAL, 2007).

18 Avaliação Ambiental Estratégica é o procedimento sistemático e contínuo de avaliação da qualidade do meio ambiente e das consequências ambientais decorrentes de visões e intenções alternativas de desenvolvimento, incorporadas em iniciativas tais como a formulação de políticas, planos e programas (PPP), de modo a assegurar a integração efetiva dos aspectos biofísicos, econômicos, sociais $e$ políticos, o mais cedo possível, aos processos públicos de planejamento e tomada de decisão [...]. Entre os instrumentos cujo emprego deve se compatibilizar com o da AAE, situam-se os de promoção da sustentabilidade, como as estratégias nacionais de sustentabilidade, os programas nacionais de política ambiental, os planos operacionais de gestão ambiental, as Agendas 21 - gerais ou setoriais, nacionais, regionais ou locais (MMA, 2002: 15; 19).
} 


\section{CONCLUSÕES}

Os desafios para a percepção e superação dos problemas socioambientais decorrentes da poluição industrial e dos seus agentes causadores e associados são amplos, profundos e complexos, pois os mesmos estão imbricadamente impregnados nas interações socioeconômicas regionais e supra regionais, atuando, muitas vezes, como pérfida moeda de troca entre a miséria social e a destruição ambiental, imposta como inevitável às populações por seus simbólicos representantes. Contudo, tanto esta mesma situação, como os impactos socioambientais da poluição industrial são resultantes de um processo histórico de condicionamento cultural, construído de modo a estabelecer um cenário no qual tais situações sejam coletivamente percebidas como "naturais", ou mesmo que não sejam percebidas (isto é, sejam "invisibilizadas").

Se tais construções são produtos que vem sendo arquitetados ao longo do processo histórico, como tais inevitavelmente deixaram registros de suas intenções, procedimentos e resultados, portanto são objetivamente rastreáveis pela História Ambiental; similarmente, os condicionantes e as implicações dos mesmos no tecido socioambiental foram moldando evidencias inequívocas quanto ao modus operantes e a identidade dos seus mentores, vinculando-os como beneficiários e responsáveis diretos pelos mesmos perante a (In)Justiça Ambiental. Assim, a aproximação entre as concepções, as técnicas e os processos destes campos do conhecimento podem colaborar na (des)construção de tal cenário perceptivo, pela demonstração material do contexto, da intencionalidade e dos agentes geradores do mesmo, possibilitando então a (re)construção coletiva e participativa de um novo e autentico cenário de Justiça Social, no qual não haja admissibilidade ética para a reprodução ou perpetuação de quaisquer atividades poluidoras, por contrariarem as condições indispensáveis a manutenção da qualidade de vida, humana e não humana.

Para a construção coletiva e participativa deste novo cenário e processo de desenvolvimento, no qual a economia esteja sujeita e adaptada às características, estrutura, funções e limites da capacidade de suporte dos seus socioecossistemas, sendo planejada e conduzida de modo a viabilizar a promoção da Justiça Social, de modo 
autossustentável, será necessário repensar o modelo e espaço-tempo gerador e difusor do conhecimento na comunidade, a sua Universidade. Esta responsabilidade, embora coletiva, para o seu desencadeamento, depende da proatividade e envolvimento daquela parcela dos seus quadros funcionais mais diretamente engajados com uma visão e postura social da instituição, abrindo-a a partir de dentro - para o conjunto da sociedade -, rediscutindo sua própria forma de organização e as melhores formas de participação no processo de tomada de decisão sobre as alternativas quanto ao modelo de desenvolvimento regional desejável e aceitável para suas comunidades.

\section{REFERENCIAS}

AGOSTINETTO, Dirceu; PUCHALSKI, Luis E.A; AZEVEDO, Roni; STORCH, Gustavo; BEZERRA, Antonio J. A; GRÜTZMACHER, Anderson S. Caracterização da Fumicultura no Município de Pelotas, RS. Rev. Bras. Agrociência, 06 (02): 171-175, Maio-Agosto/2000.

BUNDT, Angela C.; AVILA, Luis Antonio; PINTO, Jesus J. Oliveira; SANTOS, Tiago Torres; AGOSTINETTO, Dirceu; Martins, Karen. Transporte ascendente da mistura formulada de Imazethapyr e Imazapic em resposta à profundidade do lençol freático. Ciência Rural (Santa Maria, RS), 43 (09): 1597-1604, Setembro/2013. Disponível em: $<$ http://www.scielo.br/scielo.php?script=sci_arttext\&pid=S010384782013000900010>.

ACSELRAD, H.; et al. Desigualdade ambiental e acumulação por espoliação: o que está em jogo na questão ambiental? E-cadernos CES: 164-183, 2012.

ALMEIDA, A. C. C. Mulheres e Sindicato: a relação entre as trabalhadoras da indústria de construção naval e "off shore" e o sindicato dos metalúrgicos em Rio Grande, RS. Dissertação de Mestrado (Programa de Pós-Graduação em Geografia). Rio Grande, RS: FURG - Universidade Federal do Rio Grande, $2015(180$ p). Disponível em: <www.posgeografia.furg.br/index.../dissertacoes?...mulheres-esindicato...entre-as-trabalhadoras...>.

BENDATI, M. M. A.; DICK, T. Avaliação das Concentrações de $\mathrm{Cd}$, $\mathrm{Cr}$, $\mathrm{Pb}, \mathrm{Cu}$ e Zn em Água, Sedimento e Neocorbicula limosa (Mollusca: Bivalvia) no Sistema do Guaíba (RS). In: Anais do Congresso Brasileiro de Limnologia (São Carlos, SP: 2007). Disponível em: 
<http://www.ecologia.ufrgs.br/lagoguaiba/eventos/MostraTrabalhos/trabalh os/07-metaisNeocorbicula.pdf> (acesso em: 12/ Fevereiro/2013).

BRASIL. Constituição da República Federativa do Brasil (texto constitucional promulgado em 05/Outubro/1988, com as alterações adotadas pelas Emendas Constitucionais nos 1/1992 a 68/2011, pelo Decreto Legislativo no 186/2008 e pelas Emendas Constitucionais de Revisão nos 1 a 6/1994). Brasília, DF: Centro de Documentação e Informação da Câmara dos Deputados, 2012 (446 p.), $35^{\mathrm{a}}$ ed. Disponível em: <bd.camara.gov.br/bd/bitstream/handle/bdcamara/.../constituicao_federal_3 5ed.pdf> (acesso em: 19/Abril/2017).

CARSON, Raquel. Primavera silenciosa (tradução de Raul Polillo). São Paulo: Melhoramentos, 1969 (305 p). $2^{\mathrm{a}}$ ed.

DEMORE,J.P. Aspectos Sedimentares do Estuário da Lagoa dos Patos e sua Interação com a Poluição por Petróleo: subsídios para um plano de contingência. Trabalho de Conclusão de Curso (Bacharelado em oceanologia). Rio Grande, RS: FURG - Universidade Federal do Rio Grande, 2001.

FARIAS, Regina Cláudia Gondim Bezerra. Estado Minimo, para quem? : uma reflexão sobre Estado, política, privatizações e democracia no Brasil e na Argentina (14 p). In: XIII Congreso Internacional del CLAD sobre la Reforma del Estado y de la Administración Pública (Buenos Aires, Argentina: 04-07/Noviembre/2008). Disponível em: <http://portal.tcu.gov.br/biblioteca-digital/estado-minimo-para-quem-umareflexao-sobre-estado-politica-privatizacoes-e-democracia-no-brasil-e-naargentina.htm>

FEIJÓ, F. T; MADONO, D. T. Polo Naval de Rio Grande: potencialidades, fragilidades e a questão da migração (22 p). In: Anais - Encontro de Economia Gaúcha (Porto Alegre, RS: Universidade Federal do Rio Grande do Sul, 2012).

FERREIRA, Washington. A "Invisibilidade" dos Impactos Socioambientais da Poluição Industrial no "Mar de Dentro" (Estuário da Lagoa dos Patos, Rio Grande, RS) na Produção Acadêmica da Pós-Graduação em Oceanografia da FURG (pp: 289-332). In: MOURA, Gustavo Goulart Moreira (Org.). Avanços em Oceanografia Humana: o socioambientalismo nas ciências do mar. Jundiaí, SP: Paco Editorial, 2017 (344 p). Coleção Escritos Acadêmicos, Série Estudos Reunidos, Vol.1 (1 $1^{\mathrm{a}} \mathrm{ed}$.). . A Poluição Industrial no "Mar de Dentro" (Estuário da Lagoa dos Patos, RS) na Perspectiva da Educação Ambiental Crítica $e$ Transformadora. Rio Grande, RS: Usina de Ideias / Observatório dos 
Conflitos Urbanos e Ambientais do Extremo Sul do Brasil e Leste do Uruguai, 2016 (380 p).

. A Poluição Industrial no "Mar de Dentro" (Estuário da Lagoa dos Patos, RS) e Áreas Adjacentes (pp: 103-121). In: MACHADO, C. R. S.; SANTOS, C. F.; MASCARELlO, M. A. (Orgs.). Conflitos ambientais e urbanos: casos do extremo sul do Brasil. Porto Alegre, RS: Evangraf, 2015 ( $1^{\mathrm{a}}$ ed.).

. A Produção do PPGEA-FURG e a Poluição Industrial no Estuário da Lagoa dos Patos, RS. Competência (Porto Alegre), 07 (02): 129-144, Julho/2014.

FERREIRA, Washington; CIPRIANO, Diego M.; MACHADO, Carlos R.S. Da apropriação dos Conceitos à Realidade: a (in)sustentabilidade do modelo de desenvolvimento na planície costeira do Rio Grande do Sul. In: Anais Seminário de Pesquisa Qualitativa (Rio Grande, RS: Universidade Federal do Rio Grande, 2010).

FONSECA, S. F. A Aplicabilidade da Gestão Ambiental no Distrito Industrial de Rio Grande, RS. In: Anais do Congresso de Iniciação Científica (Pelotas, RS: 2007). Disponível em: <http://www.ufpel.edu.br/cic/2007/cd/pdf/SA/SA_01300.pdf >. (acesso em: 20/Junho/2012).

FRAGOMENI, L. P. M.; et al. Poluição por mercúrio em aterros urbanos do período colonial no extremo sul do Brasil. Química Nova (São Paulo), 33 (08): 1631-1635, 2010. Disponível em: <http://www.scielo.br/scielo.php?script=sci_arttext\&pid=S0100404220100 00800002> (acesso em: 12/Maio/2013).

FREITAS, Rosana de Carvalho Martinelli; NUNES, Letícia Soares; NÉLSIS, Camila Magalhães. A Crítica Marxista ao Desenvolvimento (In)Sustentável. R. Katál. (Florianópolis), 05 (01): 41-51, JaneiroJunho/2012. Disponível em:

http://www.scielo.br/pdf/rk/v15n1/a04v15n1.pdf>

GANDRA, E. Á; SILVEIRA, M. C. B. Rio Grande na Era do Titãs, 18801920: o movimento operário em sua fase "heroica" (pp: 81-96). In: COSTA, L. B.; FRIDERICHS, L. (Orgs.). Rio Grande século XX: olhares históricos. Pelotas, RS: Editora e Gráfica Universitária UFPEL - Universidade Federal de Pelotas, 2012.

GOLIN, Tau. Cartografia da Geopolítica e das Guerras: Brasil meridional. In: Anais Eletrônicos do XI Encontro Estadual de História (Rio Grande, RS: 23-17 Julho 2012), pp: 1585-1591. ANPUHRS. Disponível em: http://www.eeh2012.anpuh- 
rs.org.br/resources/anais/18/1346341473_ARQUIVO_Cartografiadageopoli ticaedasguerras-anpuh-rs-02-taugolin.pdf> (acesso em: 22/Abril/2017).

GOMES, Roger Walteman. A Geopolítica Portuária do Século XXI no Município de Rio Grande, RS: uma proposta de Educação Ambiental Crítica-Emancipatória. Dissertação de Mestrado (Programa de PósGraduação em Educação Ambiental). Orientador: Francisco Quintanilha Veras Neto. Rio Grande, RS: FURG - Universidade Federal de Rio Grande, 2013 (108 p). Disponível em: $<$ http://repositorio.furg.br/bitstream/handle/1/6125/0000010218.pdf?sequen ce $=1>$

HAMEISTER, Martha Daisson. O Continente do Rio Grande de São Pedro: os homens, suas redes de relações e suas mercadorias semoventes (c.1727c.1763).Dissertação de Mestrado (Programa de Pós-Graduação em História Social). Rio de Janeiro, RJ - UFRJ - Universidade Federal do Rio de Janeiro, 2002.

Disponível em:

https://www.academia.edu/11924913/O_Continente_do_Rio_Grande_de_S \% C3\%A3o_Pedro_os_homens_suas_redes_de_rela\%C3\%A7\%C3\%B5es_e _suas_mercadorias_semoventes_c.1727-c.1763_>

HOBSBAWM, E. Sobre História (tradução: Cid Knipel Moreira). São Paulo, SP: Companhia das Letras, 1998 (336 p).

JACQUES, R. J. S.; et al. Biodegradação de hidrocarbonetos aromáticos policíclicos. Ciência \& Natura (Santa Maria, RS), 29 (01): 07-24, 2007.

KESSEL, Z. Memória e memória coletiva. s/d (06 p). Disponível em: <http://www.museudapessoa.net/public/editor/mem\%C3\%B3ria_e_mem\% C3\%B3ria_coletiva.pdf>.

LAYBAUER L. Incremento de metais pesados na drenagem receptora de efluentes de mineração - Minas do Camaquã, Sul do Brasil. RBRH, 03 (03): 29-36, 1998.

LE GOFF, J. História e Memória. Campinas, SP: Ed. Unicamp, 1994.

LIMA, Letícia Maria Rêgo Teixeira; MOREIRA, Danielle de Andrade. $O$ Princípio do Poluidor-Pagador na Jurisprudência Brasileira: uma análise crítica de sua aplicação pelo Superior Tribunal de Justiça e Supremo Tribunal Federal. In: Relatórios PIBIC PUC-RJ, 2014 (20 p). Disponível em:

<http://www.puc-

rio.br/pibic/relatorio_resumo2014/relatorios_pdf/ccs/DIR/DIRLet\%C3\%ADcia\%20Maria\%20R\%C3\%AAgo\%20Teixeira\%20Lima.pdf>

Fábio Flores. Monitoramento Ambiental da Bacia Hidrográfica do Lago Guaíba (RS, Brasil), através da Utilização de Diferentes Metodologias Aplicadas a Taxocenoses de Peixes. Tese de Doutorado (PPG. Biologia 
Animal). Porto Alegre: UFRGS - Universidade Federal do Rio Grande do Sul, 2006 (234p).

LOPES, A. R. S. História Ambiental: uma demanda contemporânea. Caderno de Pesquisa (Uberlândia, MG), 23 (02): 483-497, JulhoDezembro/2010.

MAGLIO, Ivan Carlos. A Descentralização da Gestão Ambiental no Brasil: o papel dos órgãos estaduais e as relações com o poder local (1990-1999). Dissertação de Mestrado (Programa de Pós-Graduação em Saúde Pública). São Paulo, SP: FSP - Faculdade de Saúde Pública, USP - Universidade de São Paulo, 2000 (288 p). Disponível em: $<$ www.teses.usp.br/teses/disponiveis/6/6134/tde-01072008145252/.../IvanMaglio.pdf>

MMA. Avaliação Ambiental Estratégica. Brasília, DF: Centro de Informação e Documentação, Ministério do Meio Ambiente, 2002 (92 p). Disponível em: <http://www.mma.gov.br/estruturas/sqa_pnla/_arquivos/aae.pdf>

MARTINS, S. F. Friches Industrielles no Extremo Sul do Brasil: uma análise sobre o caso da cidade do Rio Grande, RS. In: Anais - Colóquio Internacional de Geocrítica (Porto Alegre, RS: 2007). Universidade Federal do Rio Grande do Sul, 2007 (09 p).

MIRLEAN, N.; OSINALDI, G. M. Impacto da Indústria de Fertilizantes sobre a Qualidade da Água Subterrânea. In: Anais do XIII Congresso Brasileiro de Águas Subterrâneas (São Paulo, 2004). Disponível em: <https://aguassubterraneas.abas.org/asubterraneas/article/view/23501>

NÓBREGA, Michele R.; KRUSCHE, Nísia. Diagnóstico Qualitativo da Poluição Atmosférica em Rio Grande, RS, 2000 a 2002. Geosul (Florianópolis, SC), 25 (50): 129-150, Julho-Dezembro/2010.

NIENCHESKI, L. F. H. Recursos vivos do mar e poluição. Revista CEJ (Brasília, DF), 12: 58-62, Setembro-Dezembro/2000. Disponível em: < http://www.cjf.jus.br/ojs2/index.php/revcej/article/viewArticle/360>

RIBEIRO, G. L. Tecnotopia versus tecnofobia: o mal-estar no século XXI. Série Antropologia (Brasília, DF), 248: 01-15, 1999. Disponível em: <http://www.dan.unb.br/images/doc/Serie248empdf.pdf>. (acesso em: 30/Dezembro/2014).

ROCHA, Tiago do Amaral; QUEIROZ, Mariana Oliveira Barreiros de. O meio ambiente como um direito fundamental da pessoa humana. Âmbito Jurídico (Rio Grande, RS), XIV (95), Dezembro/2011. Disponível em: <http://ambitojuridico.com.br/site/?artigo_id=10795\&n_link=revista_artigos_leitura $>$ (acesso em: 19/Abril/2017). 
RODRIGUES, L.; HENNIGEN, I. Jornalismo, a questão da verdade e a produção de subjetividade. Arquivos Brasileiros de Psicologia (Rio de Janeiro, RJ), 63 (03): 45-57, 2011.

SÁ, M. U. Avaliação da Mutagenicidade das Águas do Canal São Gonçalo, Pelotas, RS. Trabalho de Conclusão de Curso (Bacharelado em Ciências Biológicas). Pelotas, RS: UFPEL - Universidade Federal de Pelotas, 2006 (60 p).

SANCHEZ, Karine; FERREIRA, Washington; GALIAZZI, Maria do Carmo. Percepção Ambiental de Trabalhadores do Setor IndustrialPortuário de Rio Grande, RS. In: XV Semana Acadêmica de História - I Jornada Gaúcha de História Ambiental "História e Ambiente: olhares sobre o regional" (Rio Grande, RS: 2011). Ed. FURG.

SANTOS, C. F.; MACHADO, C. R. S. Extremo Sul do Brasil - uma grande "zona de sacrifício" ou "paraíso de poluição" (pp: 181- 204). In: MACHADO, C. R. et al. (Orgs.). Conflitos Ambientais e Urbanos: debates, lutas e desafios. Porto Alegre, RS: Evangraf, 2013a.

Conflitos Socioambientais no Extremo Sul do Brasil: debate a partir dos reflexos do Polo Naval de Rio Grande, RS (pp: 01-21). In: XVI Congresso Brasileiro de Sociologia (Salvador, BA: 10-12/Setembro/2013). 2013b.

SARAIVA, Bruno Cozza; VERAS NETO, Francisco Quintanilha. O Direito Fundamental ao Meio Ambiente, o Estado e a Justiça Ambiental. DELOS Desarrollo Local Sostenible, 06 (17): 11 p, Junho/2013. Disponível em: <http://www.eumed.net/rev/delos/17/direito-ambiental.pdf> (acesso em: 19/ Abril/2017).

SCHMIDT FERIS, E. et al. (Orgs). FURG: Projeto Político-Pedagógico (aprovado pelo Conselho Universitário em 19 de Dezembro de 2003). Rio Grande: Editora da FURG - Universidade Federal do Rio Grande, 2004 (25p).

SILVA, L. M. Metais pesados em tecidos de Chelonia mydas encalhadas no litoral do Rio Grande do Sul, Brasil. Trabalho de Conclusão de Curso (Graduação em Biologia Marinha e Costeira). Porto Alegre, RS: UFRGS Universidade Federal do Rio Grande do Sul / Imbé-Tramandaí, RS: UERGS - Universidade Estadual do Rio Grande do Sul, 2011 (40 p).

STENZEL, L.; FOELKEL, C.; GALLARDO, V.R.B. Avaliação ecotoxicológica e da genotoxicidade de produtos químicos frequentemente utilizados no processo de cozimento e branqueamento de celulose Kraft. In: Anais $-31^{\circ}$ Congresso Anual de Celulose e Papel (São Paulo, SP: 1998), ABTCP. 
THEODOSIO, N. P. Jornal Agora - vozes e falas no caso Bahamas: a Educação Ambiental e a construção da cidadania. Dissertação de Mestrado (Programa de Pós-Graduação em Educação Ambiental). Rio Grande, RS: FURG - Universidade Federal do Rio Grande, 2002.

VANZ, A.; MIRLEAN, N.; BAISCH, P. Avaliação de Poluição do Ar por Chumbo Particulado: uma abordagem geoquímica. Química Nova, 26 (01): 25-29, 2003.

VOLPI, J. H. Mecanismos de defesa. Artigo do curso de Especialização em Psicologia Corporal. Curitiba, PR: Centro Reichiano, 2008 (05 p). Disponível em: $<$ http://www.centroreichiano.com.br/artigos/Artigos/Mecanismos $\% 20 \mathrm{de} \% 2$ ODefesa.pdf $>$.

WINIWARTER, V. Abordagens sobre a História Ambiental: um guia de campo para os seus conceitos. Abordagens Geográficas, 01 (01): 01-21, Outubro-Novembro/2010.

YIN, Robert K. Estudo de Caso: planejamento e métodos. Porto Alegre, RS: Bookman, 2015 (5 ${ }^{\text {a ed. }) .}$ 
